DOLF ZILLMANN

LEI CHEN

SILVIA KNOBLOCH

COY CALLISON

\title{
Effects of Lead Framing on Selective Exposure to Internet News Reports
}

With headlines and texts held constant, the subheads of articles embedded in an Internet newsmagazine were manipulated in an overview from which articles could be selected. In a control condition, the lead, indicating deplorable happenings, was framed in a factual manner. In the other conditions, the leads were framed either in terms of conflict between feuding parties, the unfolding of disastrous occurrences, the emotional upheaval and agony suffered by the victims of these occurrences, or the economic implications of the incidents. Selective exposure to the articles was accumulated in minute intervals and automatically recorded. Leads projecting aggravated conflict or the agony over suffered misfortunes were found to foster increased reading times of the associated articles. The effects of highlighting misfortunes by themselves or of emphasizing the misfortunes' economic implications proved to be negligible, however.

Keywords: Internet news; overview function; lead framing; article choice; selective exposure; dramatic frames; conflict; misfortune; agony; economy

Framing is considered a pivotal practice in journalism. It has been suggested, in fact, that choosing a frame for a story would be the most consequential decision that journalists make (Smith, 1997). Such conviction seems to derive from the widespread and long-standing belief that news frames give meaning to events and issues and that, when used appropriately, they instigate readers' attention and interest. The latter is most salient for newspapers and newsmagazines in competitive markets. To attract readers, journalists, as

COMMUNICATION RESEARCH, Vol. 31 No. 1, February 2004 58-81

DOI: $10.1177 / 0093650203260201$

(C) 2004 Sage Publications 


\section{Zillmann et al. • Lead Framing and Selective Exposure}

they construct their reports, have to select intriguing story slants or news hooks. By giving emphasis to certain aspects and downplaying others, they can hope to capture and retain the readers' attention to the news (Gitlin, 1980; Tankard, 2001).

A sizeable amount of research has been conducted on the effects of the framing of news reports. It can be considered amply established that variations in news frames are capable of creating substantial differences in the audience's responses-in the interpretation and comprehension of the news, in particular (Cappella \& Jamieson, 1996; Davis, 1995; De Vreese \& Semetko, 2002; Iyengar, 1991; Iyengar \& Simon, 1991; Price, Tewksbury, \& Powers, 1997; Rhee, 1997; Shah, Domke, \& Wackman, 2001; Valkenburg, Semetko, \& De Vreese, 1999).

Alterations in the presentation of news reports have been found to influence the perception of events and issues as well as thoughts about, recall of, and dispositions toward them. For instance, Iyengar (1991) investigated the effects of case-focused, episodic frames versus more general, thematic frames on the attribution of responsibility concerning social problems and political issues. He found episodic framing to promote the ascription of responsibility to specific individuals or groups. Thematic framing, in contrast, was found to favor assigning culpability for social ills to society at large and to society's institutions. Cappella and Jamieson (1996) as well as Valentino, Beckmann, and Buhr (2002) demonstrated that strategic, manipulative news frames are more likely to create and enhance political cynicism than are issue-focused frames. Furthermore, Valentino, Beckmann, and Buhr (2001) found such frames to inhibit information retention. Price et al. (1997) manipulated the opening and closing paragraphs of news reports by highlighting either conflict, human interest, or event implications. These news frames were found to instigate distinctive frame-related trains of thought and feelings. Research by Valkenburg et al. (1999) led to similar conclusions. These investigators observed, in addition, that the human-interest framing of news reports was detrimental to remembering the stories' news content. Instead of focusing on the effects of substantially different frames, McLeod and Detenber (1999) examined consequences of comparatively minor variations in a single news frame. Their study revealed a negative relationship between various degrees of emphasis of normative ("status quo") precepts in news commentary and the audience's support for a depicted protest demonstration. In a two-wave experiment, Tewksbury, Jones, Peske, Raymond, and Vig (2000) explored the short- versus long-term effects of somewhat more explicit advocacy framing and found strong short-lived effects that dissipated rapidly over time.

Framing research has uncovered and identified a great many news frames of relevance. Some of these frames are issue-specific (e.g., Bantimaroudis \& 
Communication RESEARCH • February 2004

Ban, 2001; Davis, 1995; Hertog \& McLeod, 2001; Jasperson, Shah, Watts, Faber, \& Fan, 1998). Such frames apply to unique events or issues, differ from case to case, and thus have limited generalizability. Other frames are repeatedly and consistently employed and permeate much of the news (e.g., Neuman, Just, \& Crigler, 1992; Price et al., 1997; Semetko \& Valkenburg, 2000; Valkenburg et al., 1999). It has been observed that American news writers use so-called conflict, economic-consequences, human-impact, and morality frames with considerable regularity (Neuman et al., 1992; Price et al., 1997).

Tankard (2001) enumerated several news features that commonly convey frames. They are headlines and kickers, subheads, photographs, photo captions, and leads, among others. These features are the means through which news frames are made salient (Bantimaroudis \& Ban, 2001). Most commonly, the first paragraph of a news story functions as the lead, but subheads often serve in this capacity also (Fox, 1993; MacDougall \& Reid, 1987).

Some journalists write leads as summaries composed of fact-filled statements. In view of the readers' apparent interest in more than cut-and-dried reporting, others are deliberate in insinuating and suggesting intrigue and human drama that is connected with the plain facts. Toward that end, the conflict frame has been used as one of the principal devices. Journalists and researchers alike acknowledge conflict as the dominant frame in U.S. news reporting (MacDougall, 1968; Neuman et al., 1992; Richards, 2001; Smith, 1997). Clashes between opposing forces-be they warring nations, political parties, bickering neighbors, or jealous lovers-have been the stuff that made news through the ages. Not surprisingly, then, journalists seem to have a core belief that conflict makes news (Fallows, 1996; Garrison, 1990; Smith, 1997). Journalists therefore tend to accentuate dramatic confrontation in existing conflicts, or they tailor an issue so as to fit the conflict frame (Richards, 2001).

Neuman et al. (1992) found that, next to conflict, the human-impact frame is commonly employed in the news. This impact frame combines, and thus confounds, emphasis on human misfortunes and the human suffering it causes. The saying that "if it bleeds, it leads" has been declared the motto under which much American journalism operates (Fallows, 1996). Accordingly, accidents and disasters make up a disproportionate share of news reporting (Haskins, 1984). So-called sob news apparently holds great appeal (Fallows, 1996; Garrison, 1990). MacDougall (1968) suggested that "our interest in the lives and welfare of others and in the well-being and progress of mankind as a whole... [leads] us to read ... of loss of life and property in communities (i.e., misfortune of individuals and their sufferings)" (p. 68). To capture the readers' interest with the lead-ins of stories, journalists thus 


\section{Zillmann et al. • Lead Framing and Selective Exposure}

spell out death and injury, property damage, and financial losses, along with the devastation that these happenings bring to their victims (Fox, 1993). Journalists do so in different ways, however. Some focus on the misfortunes that people experience, whereas others detail and dwell on the human impact — that is, on people's agony, despair, and grief_-in efforts at making their stories emotionally compelling. But as indicated earlier, yet others see sufficient human drama in the infliction of economic loss and devastation, and they consequently work economic considerations into their reports (Neuman et al., 1992; Semetko \& Valkenburg, 2000).

To date, framing studies have concentrated on the cognitive consequences of news presentations with particular frames, mostly the shaping and modification of information processing and retention. In contrast, the potential effects of frames on selective exposure to the news have received almost no attention. It has, of course, been speculated all along that cleverly chosen leads will entice readers to read, listeners to listen, and viewers to keep on watching. But a firm linkage between frames and the selection and the consumption of news has not as yet been established. Scheufele (1999), after classifying the various approaches to studying effects of framing in an exhaustive recent review, was unable to identify investigations of the implications of specific news frames on selective news reception.

Some recent investigations exist, however. To the extent that the use of imagery connected with written or spoken reports can be considered framing (Tankard, 2001), research did establish a relationship between frames and selective exposure. Specifically, so-called agonistic, danger- and distressconveying images embedded in printed newsmagazines have been found to foster longer reading periods and superior retention of news items than did the involvement of images with innocuous content or text without images (Zillmann, Knobloch, \& Yu, 2001). In a parallel investigation, the use of agonistic images in the overview and in articles of Internet newsmagazines proved equally effective in drawing readers to these articles and in fostering prolonged reading times (Knobloch, Hastall, Zillmann, \& Callison, 2003). If such usage of agonistic imagery is construed as human-impact framing, framing of this kind can be considered more effective than framing of the more innocuous variety. Moreover, the Internet investigation, by using images in the article overview, suggests that the early application of humanimpact frames-essentially, lead framing-may be particularly effective in bringing attention to the associated reports.

The possibility that the framing of written leads may have comparable effects on selective exposure has been examined by Chen and Zillmann (2002). These investigators created a printed newsmagazine with several 
Communication RESEARCH • February 2004

lead-frame manipulations. A straightforward account of events in the subhead defined the control condition, labeled a factual frame. A subhead describing the hostile confrontation of two parties served as the conflict frame. Because the human-impact frame, as indicated earlier, tends to confound accounts of misfortunes with accounts of people's suffering in their wake, this frame was broken down into two: a misfortune frame detailing experienced calamities and catastrophes without dwelling on their emotional aftermath, and an agony frame that, although necessarily indicating misfortunes, focused on emotional upheaval-apprehensions and fear, anger and rage, and despair and grief. Finally, an economy frame addressed the monetary consequences of reported happenings. The reading of the framed articles was measured in line-by-line eye movement. It was unobtrusively recorded and timed, following the procedures used by Zillmann et al. (2001). Both the conflict and agony frames were found to foster significantly increased reading times of the associated articles. Equal in magnitude, the enhancement effect of these two frames was in comparison to all other conditions. The misfortune and economy frames, although showing a tendency toward increased reading times, failed to differ appreciably from the time of the factual control condition.

The present investigation builds on this initial lead-framing study. However, rather than investigating selective-exposure effects as a function of lead frames in printed newsmagazines that require an examination of the magazine's pages, the present study seeks to establish framing effects for Internet newsmagazines in which article choices are made from overviews. As a rule, readers of Internet magazines do not sample articles blindly and thus cannot make reading decisions on the basis of quickly screening the actual reports. Their choices are made on the limited information provided in the overview's headlines and subheads. This circumstance ensures that, comparatively speaking, the headings determine selections to a greater degree and hence give their framing greater decisional influence. It may therefore be expected that the effects of lead framing are more pronounced for Internet newsmagazines than for printed news magazines.

On grounds of the framing effects observed by Chen and Zillmann (2002), the following expectation may be stated.

Hypothesis 1: Lead framing in the overview of Internet newsmagazines in terms of conflict or agony, compared to such framing in terms of misfortune or economic considerations as well as to plain factual framing, increases selective-exposure time to the associated news reports. 


\section{Zillmann et al. • Lead Framing and Selective Exposure}

Methodologically, this investigation adopts the automated procedures used in the research by Knobloch, Dillman Carpentier, and Zillmann (2003) and Knobloch and Zillmann (2002).

\section{Method}

\section{Overview}

An experimental Internet newsmagazine was created and made to look like those available on the World Wide Web. Accessible articles were displayed in a browser frame, with a logo bar on top and a navigation bar at the left. Interactivity was also similar to other Internet newsmagazines. Specifically, an overview presented hyperlinks with the headlines and subheads/leads of articles, and respondents could click these hyperlinks for access to the articles and, in addition, hyperlinks within the articles for return to the overview. A scroll bar at the right enabled the perusal of selected articles. Research participants were instructed to follow their own personal interest in sampling among the articles. It was explained that time would not allow them to read all articles and that they should feel free to read whatever they wanted and as much of it as they wanted. The magazine featured nine articles that competed for the readers' attention. The topics of all articles were of general interest. About half the time needed to read the magazine in its entirety was provided. The subheads of four of these articles presented the reported events either in a factual manner or in terms of conflict, misfortune, agony, or economy. These five versions defined the frame manipulation. For the remaining five articles, the leads were not manipulated. They differed, however, in that each expressed one of the five frames, thereby ensuring that two articles of like frame were always present when choices were made from the overview. In addition, although the body of all accessible articles was kept constant, all subhead-manipulated articles featured portions pertaining to all five frames. This was done to ensure that the text relates to the lead in all framing conditions - or alternatively expressed, to avoid that the readers could feel misled by a lead if it had no resemblance to the article text. Moreover, to rule out that early-placed frame portions within the constant texts of articles could function as secondary leads and thus systematically affect reading, the order of these portions was randomly varied across the four articles with the same lead manipulation. Unbeknownst to the respondents, the Web display logged exposure times (i.e., the time respondents spent with the screen pages of each and every article as well as with the overview). After the partial reading of the newsmagazine, participants estimated how much they thought to have read of the articles with manipulated leads. 
Communication ReSEARCH • February 2004

\section{Research Participants}

One hundred and eleven research participants, 77 males and 34 females, were recruited from undergraduate communication classes at a large American university. The participants were promised and received extra course credit for participation. They were randomly assigned to the experimental conditions. Gender was evenly distributed throughout all conditions. The average age of the male participants was 19.97 years and that of the female participants 20.09 years.

\section{Procedure}

Sessions were conducted in a laboratory with 15 identical personal computers with 14-inch monitors. Participation per session varied from 2 to 15 persons. An experimenter met participants at the laboratory and seated them at the computers that were separated by partitions, such that the respondents could only see the screen of their own monitor. Initially, all monitors displayed the same text, outlining procedure and giving directions. All instructions were presented in easy-to-read, 20-point onscreen size.

Respondents were informed that they would partake in an investigation of Internet newsmagazines and asked to consent to participate. None refused. After consent was obtained, they were asked to read and follow the instructions on the screen. The respondents were informed that they would browse, for a limited period of time, a standard Internet news site containing various articles of general interest and that thereafter they would evaluate some aspects of the magazine on an automatically launched questionnaire. The participants were asked to read whatever they would find interesting until the questionnaire presented itself. After a final review of directions provided on the computer screen, the experimenter told the participants to click the "start" box and begin selecting and examining the news stories. The specific reading instructions were as follows:

Please inspect the overview, and pick and choose whatever you find interesting. You can look at the headings and subheadings, then click to the stories you find interesting, and peruse the news reports as you wish. If an article seems interesting initially but then disappoints you, don't feel obligated to read it to the end. Click to return to the overview and keep on searching for the things that interest you-much as you would do in the privacy of your home. After you read some of the news reports, in part or in their entirety, we would like you to answer a few quick questions about your impressions. 


\section{Zillmann et al. • Lead Framing and Selective Exposure}

By clicking the "continue" box, participants accessed the overview screen that listed all available articles by headline-subhead. The respondents then made their selection by clicking on the hyperlink of an article, scrolled through the selected article, read as much of it as they cared to, clicked to return to the overview, selected another article (or returned to the abandoned one), and so forth to the end of the 10-min reading period. At the end of this preset reading time, the application jumped to screens that indicated the conclusion of reading and presented the questionnaire soliciting information about the reading of the articles with manipulated leads. It also assessed the respondents' gender and age. After completing the questionnaire, the research participants were debriefed and thanked for their assistance, initially by statements on the screen and then personally by the experimenter.

\section{The Experimental Internet Newsmagazine}

Display of available articles. The overview screen featured the fictitious magazine title "WORLDnews.com" in a banner spanning the top, along with a colorful world map logo. At the left, it presented a deactivated navigation bar listing a variety of news categories. The headlines and leads of the nine articles were arranged in two columns separated by a thin line. Headlines were in 16-point onscreen size, bold, and bright red. The leads below the headlines were in 16-point onscreen size and black. At the end of each lead was a hyperlink to access the full article. The link was presented by the word "More" in 16-point onscreen size, in bright blue, and underscored. The order of the articles was such that odd numbers carried stories with unmanipulated leads, whereas even numbers carried stories with manipulated leads. Moreover, the sequence of articles was systematically alternated ( 1 through 9 versus 9 through 1 ).

Display of the articles proper. The magazine's title and logo as well as the deactivated navigation bar were retained throughout the presentation of articles. Each article was presented with its headline and subhead from the overview. Headlines were in 24-point onscreen size and bright red. Subheads were in 18-point onscreen size, bold, and black. The story text proper was also in 18-point onscreen size and black but not in bold. Independent of scrolling, a bright red box with the 18-point onscreen size black inscription "Return to Front Page" was obtrusively displayed at the lower left of the text.

Articles with manipulated leads. The articles with differently framed subheads had the following headlines: Article 2: Troubled Waters (a story on shark attacks at Florida beaches); Article 4: E. coli Strike Again (a story on 
Communication ReSEARCH • February 2004

food poisoning from tainted meat); Article 6: Carjackings on the Rise (a story on the crime of violent car theft); and Article 8: New Jersey Roller Coaster Accident Kills Two (a story on the risks of injury from coaster rides). The average length of these articles was 644 words.

Frame manipulation of leads. Five frame versions were created for each of the subheads/leads of the four manipulated news reports. The factual frame presented events and issues in a straightforward fashion-that is, without dramatic embellishments and without indication of implications. This frame constituted the control condition for the determination of effects from added dramatic elaborations or the suggestion of salient consequences. All other frames entailed the essentials of the factual frame but then added information that defined the alternative frames. The conflict frame emphasized the hostile confrontation of individuals or groups in pursuit of diametrically opposite goals. The misfortune frame indicated the victimization of people in terms of loss of possessions, health, or life. It did so without involving conflict between opposing parties. The agony frame reported such victimization in emotional terms, focusing on people's suffering during and following experienced adversity. The agony frame may thus be considered an extension of the misfortune frame. It obviously entails misfortune but then dwells on the torment and the plight of victims. The economy frame gave attention to the economic circumstances and consequences of the reported events and issues. In the employed story on food poisoning, for example, the factual frame reported patrons' illness from eating contaminated food in a restaurant; in the conflict frame, the victims of the food poisoning clashed with restaurant executives, threatening legal action; the misfortune frame described the ill effects of food poisoning and the victims' hospitalization; in the agony frame, the victims' emotional and psychological suffering was dramatized and highlighted; and in the economic frame, the likely monetary consequences of the unfortunate incident were outlined. The manipulation of the lead of this and the other three articles is detailed in Table 1.

Across articles, the leads varied substantially in length: 44, 42, 25, and 67 words for articles $2,4,6$, and 8, respectively. Within each article, the leads were of identical word length across all frame conditions, however.

Articles with unmanipulated leads. These articles were included to compete with the manipulated articles for the readers' attention. Their headlines were as follows: Article 1: West Nile Virus on the Move (a story about the spread of West Nile Fever southward along the eastern seaboard); Article 3: Environmental Groups Protest Soft Pollution Law (a story on clashes between environmentalists and legislators concerning air and water 


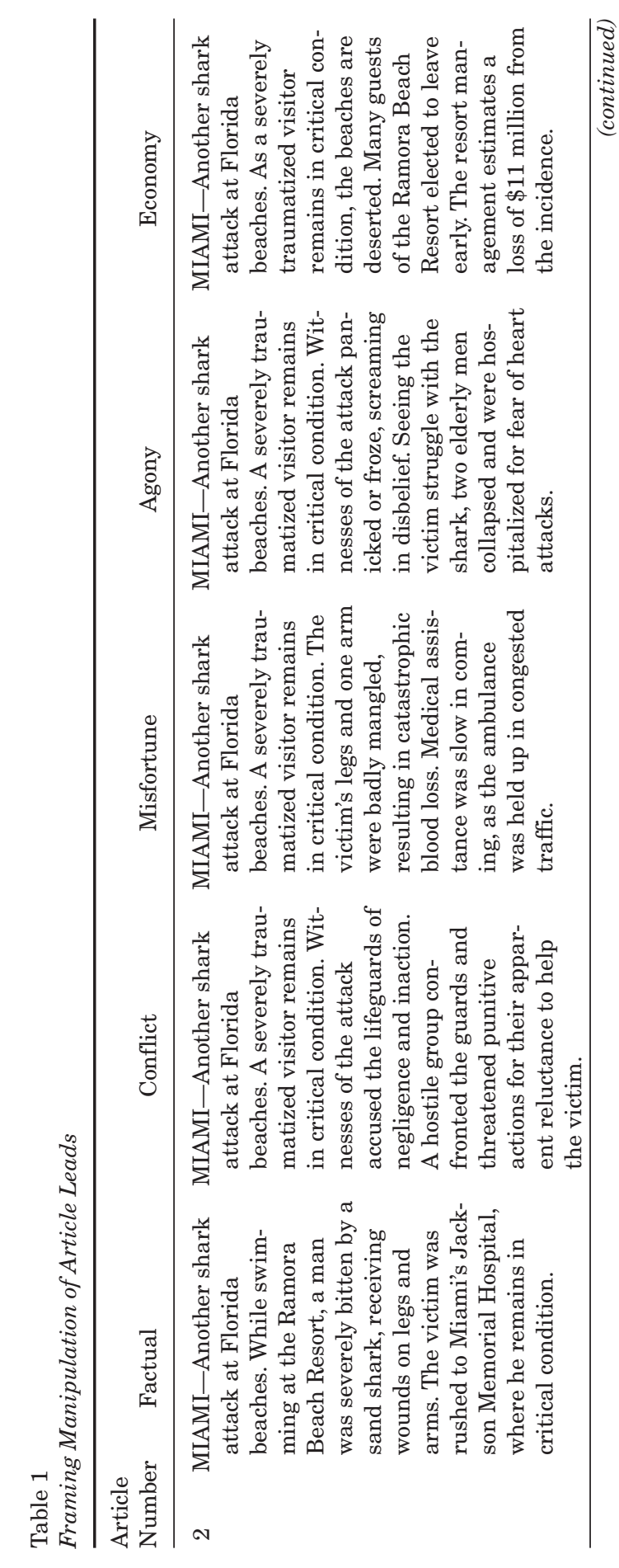




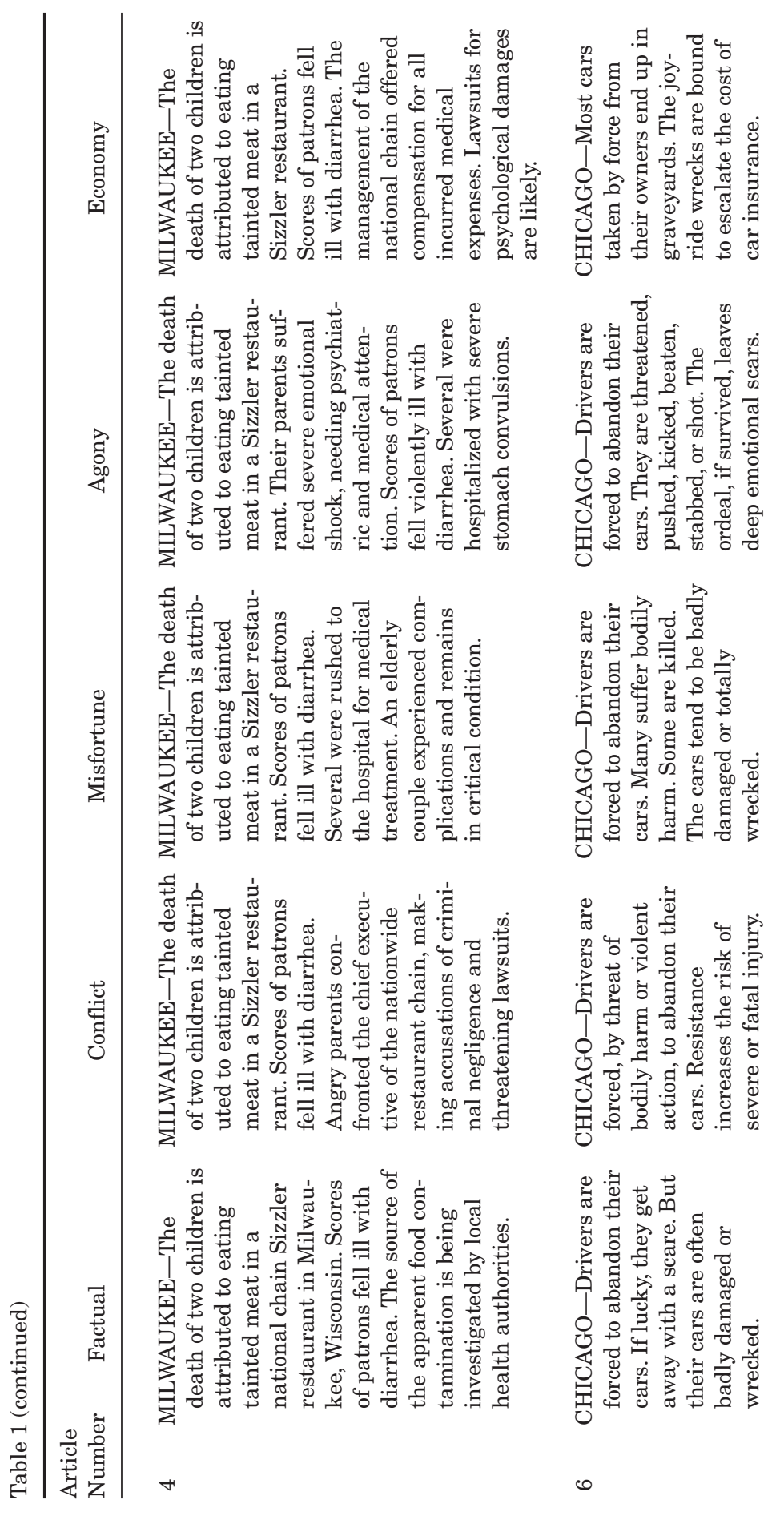




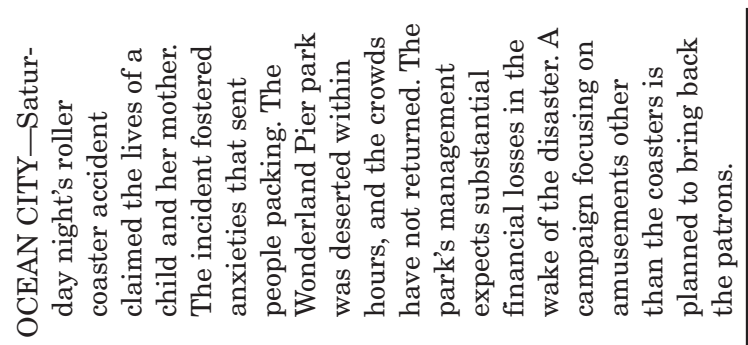

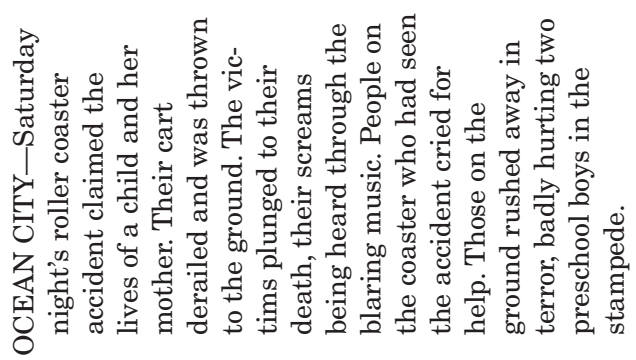

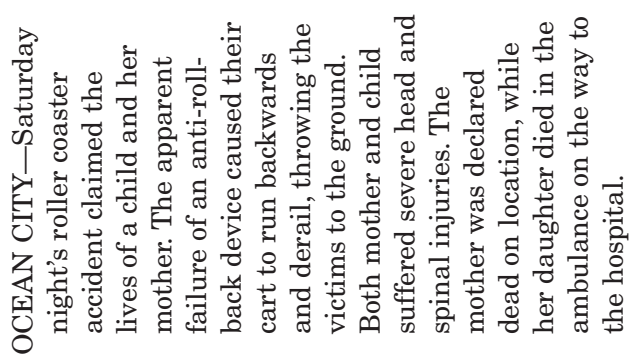

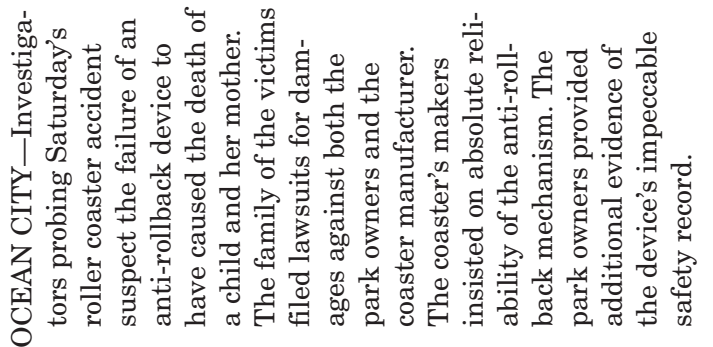

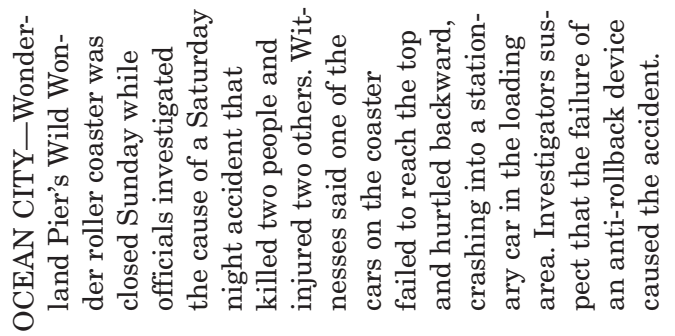
$\infty$ 
Communication ReSEARCH • February 2004

pollution); Article 5: Boat Collision (a story about a ferry disaster in the Florida Keys); Article 7: Break-Ins Running Rampant in Ritzy Homes (a story about burglaries in wealthy gated communities); and Article 9: Helmets to Be Mandatory for Kids Riding Mini-Scooters (a story about the fight over restrictive legislation concerning collapsible small-wheel kickboard scooters). The stories averaged 551 words.

All employed articles were taken from common news sources. Stories with unmanipulated leads were largely as found. Stories with manipulated leads were substantially edited, however, to accommodate experimental needs. The leads of these stories were mostly created, disregarding actual happenings.

\section{Measures of Selective Exposure}

Recorded time. Unbeknownst to the respondents, their hyperlink usage was monitored and placed into a log file. This procedure produced a record of the duration of time that respondents visited each and every article. It also recorded the amount of time during which the overview received attention. In case of repeated entries/exits, the duration of the multiple exposures was accumulated to a single measure of exposure time. The software (created with Macromedia Authorware) summed exposure times in preset 1-min intervals for each article per each respondent, thereby providing the means to trace over-time developments of selective exposure. All data were automatically collected in files for analysis.

Recalled time. Retrospective estimates of time spent reading the focal articles were also automatically collected in the indicated data files. The questionnaire presented at the end of the 10-min reading period asked respondents to indicate how much, in terms of portions of text, they remember reading. This was done for the four articles with manipulated leads only. The articles were reinstated by their headlines. For each article, a four-box scale was provided. From left to right, the boxes were labeled "none of it" (0), "about one quarter of it" (1), "about half of it" (2), "about three quarters of it" (3), and "all of it" (4). Estimates were entered by clicking one of the boxes for each story. Although estimates could be altered prior to moving on to the next story by clicking "continue," only one estimate per story was accepted by the software. Respondents then entered their gender by clicking the appropriate box and their age by typing in a two-digit number of years. Finally, the debriefing screen came on, concluding the measurement procedure. 


\section{Zillmann et al. • Lead Framing and Selective Exposure}

\section{Results}

\section{Recorded Time of Selective Exposure}

The exposure-time data, accumulated in minute blocks, were initially subjected to analyses of variance that included the two sequences of article presentation in the headline-subhead display as a factor (order, reversed order). For all manipulated articles, each level of time of measurement was examined. In none of these analyses did sequence yield appreciable main effects or interactions with other variables (i.e., with lead frame or gender of respondent). The order of articles in the headline-subhead display was thus considered immaterial and excluded from further analysis.

With sequence collapsed, the accumulated exposure times were summed across the four manipulated articles and analyzed at each level of time of measurement (min 1 through min 10) in a lead frame (factual, conflict, misfortune, agony, economy) by gender design. These analyses yielded the framing effects shown in Table 2 . As can be seen, the differentiation was initially insignificant (up to min 3) but soon (in min 4) reached and then retained (through min 10) significance. Comparisons of means subsequent to significant frame main effects indicate that both the conflict and agony frames caused respondents to spend more time reading the articles that were subheaded by these frames. As shown in Table 2, the effect of the agony frame proved to be particularly strong, manifesting itself in the sixth minute. The effect of the conflict frame materialized somewhat more slowly in the eighth minute. The statistical decisions concerning these effects are summarized in Table 2. All significant frame effects proved to be uniform across respondent gender, as no appreciable variation was observed in the gender main effects ( $F<1$ in seven cases and $p>.10$ in the remaining three) and in the gender interactions with lead frames $(F<1$ in five cases and $p>.10$ in the other five).

To learn about possible interactions between frame and the four manipulated articles, the articles were used as a repeated-measures factor and crossvaried with frame. As gender was found to be inconsequential, gender was collapsed in these analyses. The frame by articles design was then applied to all levels of time of measurement.

The analysis yielded significant main effects for articles (GreenhouseGeisser corrected, $p<.001$ for all levels of time of measurement). The article on food poisoning showed consistently shorter exposure times than the other articles. At the 10-min level, for instance, this article averaged only $42.54 \mathrm{sec}-$ onds, whereas all other articles yielded significantly $(p<.01$ by $t$ test) longer 


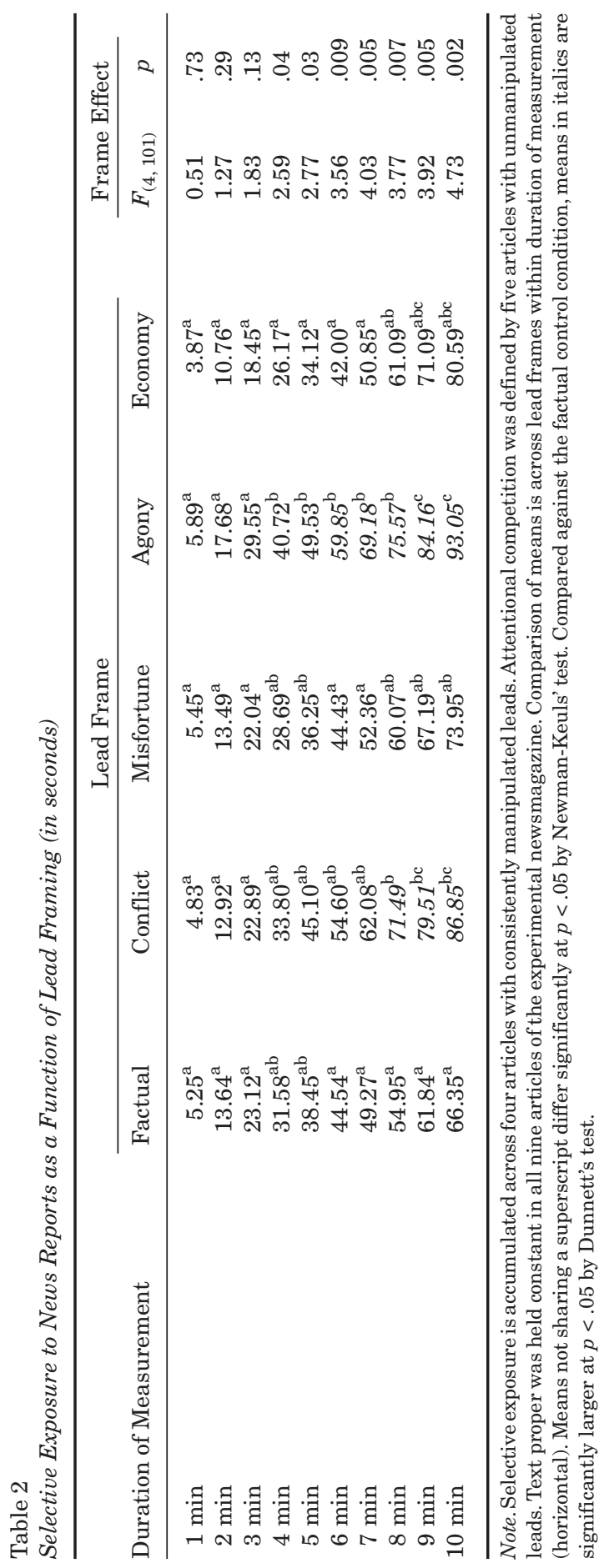




\section{Zillmann et al. • Lead Framing and Selective Exposure}

times: $M=94.40$ seconds for the flood article, $M=87.29$ seconds for the carjacking article, and $M=94.72$ seconds for the roller-coaster article.

In contrast, the more important interactions between frame and articles were insignificant throughout, yielding $F<1$ for all levels of time of measurement. This finding indicates that, despite overall variation in the reading time of articles, the effects of lead frames were uniform across articles. In these mixed-measures analyses, the main effects of frame are, of course, those reported in Table 2 .

The uniformity of the frame effects is further shown by the analysis of averaged unaccumulated exposure-time data ( $\mathrm{sec}$ per min). In the mixedmeasures frame by articles design, the main effect of frame, $F(4,106)=4.80$, $p=.001$, as well as that of articles, $F(3,318)=8.67, p(\mathrm{G}-\mathrm{G}$ corrected $)<.001$, were significant. In contrast, the interaction was associated with $F<1$. The article comparison shows again the lower $(p<.01$ by $t$ test) exposure times for the food-poisoning story, $M=4.30$. The other articles yielded means of 9.50 , 8.70 , and 9.57 for the flood, carjacking, and roller coaster stories, respectively.

To examine the exposure differences over time statistically, the unaccumulated exposure times were subjected to a frame by time of measurement mixed-measures analysis of variance. This analysis yielded the already reported main effect of frame, $F(4,106)=4.80, p<.001$, and a significant main effect of time of measurement, $F(9,954)=4.10, p(\mathrm{G}-\mathrm{G}$ corrected $)=.001$. The interaction of these factors proved insignificant, however: $F(36,954)=1.09$. Given the absence of an interaction, the time of measurement main effect merely reflects the rapid increase ( $p<.01$ by $t$ test) in exposure time from min 1 to $\min 2$, with $M=5.05$ and $M=8.59$, respectively. All other times varied negligibly around their mean of 8.26 .

The sharp increase in exposure times across articles is obtrusively displayed in Figure 1, which expresses these changes in portions of time available for reading. This finding is readily explained as a result of the respondents' initially longer perusal of the screen displaying the headlines and subheads of all articles. As the times of such perusal were recorded, the minute-by-minute data were analyzed in a mixed-measures analysis of variance, with frame as an independent-measures factor and time of measurement as the repeated-measures factor. A significant main effect of time of measurement emerged: $F(9,954)=53.43, p(\mathrm{G}-\mathrm{G}$ corrected $)<.0001$. Both the main effect of frame and the interaction with time of measurement were negligible, however, $F<1$ and $F(4,106)=1.13$, respectively. The average overview-perusal times started at min 1 with $28.43 \mathrm{sec}$ and then diminished toward $\min 10: 8.78,5.99,4.52,6.17,5.36,5.26,6.51,6.56$, and 5.41. By $t$ test, the min 1 time exceeds all other times at $p<.01$, but differences between all remaining times fail to meet the $p<.05$ criterion. 


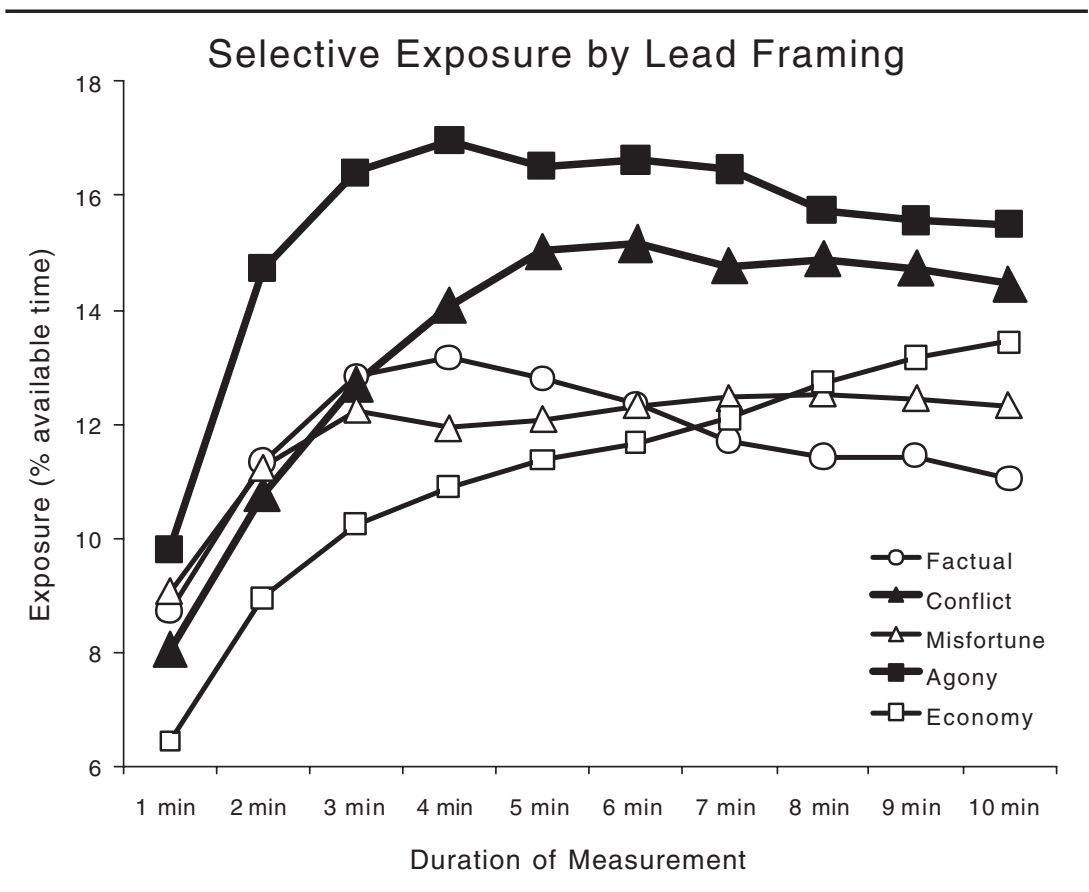

Figure 1. Times of Exposure to Articles as a Function of Differently Framed Subhead Leads in the Overview

Note. The low initial reading times reflect the examination of the overview for orientation.

Expressed as a portion of available screen time, the accumulated (rather than averaged) perusal times convert to a series of consecutively shorter times. From min 1 through min 10, the percentages were 47, 31, 24, 20, 18, 16, $15,15,14$, and 14. This pattern is consistent with the argument that the respondents' need for orientation was initially substantial but then diminished quickly as an overview had been achieved and choices could be made more expediently.

\section{Recalled Time of Selective Exposure}

After initial analyses failed to indicate gender differences, gender was collapsed and the recall data subjected to a mixed-measures analysis, with frame as an independent-measures factor and the manipulated articles as a repeated-measures factor. Only the main effect of articles proved to be significant: $F(3,318)=7.48, p(\mathrm{G}-\mathrm{G}$ corrected $)<.0001$. Both the frame main effect and the frame-articles interaction were associated with $F<1$. Respondents were thought to have read the least of the food poisoning article $(M=1.47)$. Estimates of reading were similarly low for the carjacking story $(M=1.85)$. 


\section{Zillmann et al. • Lead Framing and Selective Exposure}

Estimates of having read the roller coaster and flood articles, in contrast, were appreciably higher ( $M=2.38$ and $M=2.32$, respectively) and significantly different ( $p<.01$ by $t$ test) from the reading estimates of the other articles. This recall pattern reflects recorded exposure times only in that respondents seem to have recognized that they read the least of the food poisoning article and more of the others. It is glaringly discrepant, however, in that the roller coaster article fostered substantial recorded reading times, whereas respondents recalled having given it little attention. Moreover, the recall pattern does not at all reflect the recorded exposure differences caused by lead framing.

The correspondence between the recorded times of reading and of the recalled amounts of that reading was further examined by correlational analyses. The degree of correspondence was found to be more satisfactory than that observed in the comparisons of means as indicators of central tendencies. The correlation coefficients were $.64, .77, .80$, and .75 for the flood, food poisoning, carjacking, and roller coaster articles, respectively, all associated with $p<.0001$.

\section{Discussion}

The findings support the hypothesis that conflict and agony frames of leads displayed in the article overview of Internet newsmagazines foster greater selective exposure to their respective articles than do alternative, commonly employed frames. Specifically, after an apparent orientation period during which some, many, or all leads of available articles were examined, readers elected to expose themselves for longer periods to the articles with conflict and agony frames. Compared against the factual-frame control condition, the conflict frame increased selective reading after $7 \mathrm{~min}$. The agony frame increased selective reading more rapidly after $5 \mathrm{~min}$. The misfortune and economy frames, in contrast, failed to appreciably elevate reading time of their respective articles at any time during selective-exposure assessment.

These findings are entirely consistent with those of the earlier investigation of lead-framing effects in the reading of printed newsmagazines (Chen \& Zillmann, 2002). This investigation also showed significant reading enhancements by conflict and agony frames-in contrast to the alternative frames, which did not affect reading times. During the 10-min period of selectiveexposure measurement, the conflict frame, relative to the factual control, elevated reading time by $18 \%$ and the agony frame elevated it by $21 \%$. In the present investigation, the elevation was notably stronger, with $31 \%$ for the conflict frame and $40 \%$ for the agony frame. This result can be considered suggestive of the pivotal influence on selective reading by the seemingly 
Communication ReSEARCH • February 2004

unavoidable overview of abstracts that, in their function as leads, characterize Internet news delivery. The greater influence may manifest itself negatively in rejection terms. Specifically, when selecting articles from an overview, intriguing leads will draw attention at the expense of less imposing ones. As the less imposing leads will not prompt selection of the associated articles, these articles are deprived of a chance to recommend themselves through features such as layout, images, excerpted quotes, or text segments of dramatic quality. In filing through a print magazine, in contrast, these features are allowed to exert their effect and thereby foster selective reading of articles for reasons other than their leads.

Independent of such likely differences in the effects of lead framing in print versus electronic news media, the repeatedly observed influence of conflict and agony frames on selective exposure is obtrusive and calls for an explanation.

One explanatory account can be derived from the contention that people are "hardwired" for attention to danger-conveying signals (Shoemaker, 1996). Such a proclivity for attention to threatening environmental conditions has been shown to have utility in safeguarding individuals and the species. Moreover, neurophysiological research has elaborated the mechanisms of this proclivity (Zillmann, 1998; Zillmann et al., 2001). The difficulty in applying the rationale to framing in the present research lies in the fact that the misfortune frame may be construed as a danger-signaling device also. Even the perhaps less immediate threats conveyed in economy frames might be considered signals of danger. Why, then, did these frames prove inconsequential for selective exposure? Is it specifically the absence of the display of human impact that makes pure misfortune and economy leads comparatively ineffective curiosity-arousing devices? For example, is the report of a fire in a nightclub that destroyed a luxurious building a compelling one only when it can detail patrons ablaze or trampled to death? It would seem to be so and, as argued, because of the signaling of danger in the display of human demise. Bringing human suffering and devastation to the fore, along with the emotional upheaval in coping with adversity under openly hostile circumstances, may thus be considered the critical ingredient that gives the agony and conflict leads their apparent power to arouse a need for further information about the reported events.

An alternative explanation focuses on human empathic sensitivities. Such sensitivities are also presumed to be hard-wired and evolved in the course of human evolution (Plutchik, 1987). Human interaction is seen to depend in large measure on the sensitivities in question. More important here, however, these sensitivities can be seen as a trap that elicits empathic reactions when they have little or no interactive utility (Zillmann, 1991, 2002). The media of 


\section{Zillmann et al. • Lead Framing and Selective Exposure}

communication are paramount in offering the conditions for such somewhat inappropriate empathic reactivity. As people learn about others' emotional experiences, their empathic sensitivities are involuntarily engaged. Emotional reactions are triggered, and these reactions foster, in turn, continued attention to and interest in the welfare of others (MacDougall, 1968). The display of emotion in the news is therefore pivotal in this approach; and as emotional displays define conflict and agony framing, lead framing of either kind can be expected to promote more reading of associated reports than does alternative lead framing. Interestingly, the empathy approach is hedonically symmetrical in that it also predicts displays of emotions of triumph and glory to occasion strong interest in the emotion-precipitating events. In this respect, the empathy rationale differs strongly from that of sole focus on danger and adversity.

In the present investigation, selective exposure was measured by the duration of exposure to screens presenting the text of particular news reports. This measure does not directly translate to reading text in the sense of processing, comprehending, and reflecting on that text. As a minimal means of validating the measure as one of reading defined as information intake, the respondents' recall of reading portions of the text of articles was also ascertained. The analysis of variance failed to yield significant effects of lead framing on that measure, probably as the result of the crudeness of the instrument (i.e., article quarters as units of analysis). The correlation between recorded selective exposure and recalled reading proved satisfactory, however: $r=.74, p<.001$. In the study by Chen and Zillmann (2002) that used identical stimulus material but measured actual line-by-line reading instead of screen exposure, this relationship was virtually the same: $r=$ $.71, p<.001$. The possible argument that the procedure employed in the present investigation measured screen staring, not reading, would seem to be rendered contemptuous by these parallel relationships. The selective-exposure measure is further validated, however, by assessments reported by Zillmann et al. (2001). In their investigation, measures of page exposure, line-by-line reading, recall of reading, and recall of text segments were taken and found to be significantly intercorrelated. The assessment of screen exposure may thus be considered to reflect information intake and storage, the latter at least for the short term.

In view of this, the selective-exposure measurement procedures that were developed for the present and similar investigations recommend themselves as unobtrusive reading assessments that are free of distortions from evaluation apprehension and related examination concerns. They offer themselves for the exploration of numerous relevant factors in information selectivity- 
Communication RESEARCH • February 2004

factors in the display of messages as well as in the idiosyncrasies of the recipients' habits and personalities.

\section{References}

Bantimaroudis, P., \& Ban, H. (2001). Covering the crisis in Somalia: Framing choices by the New York Times and the Manchester Guardian. In S. Reese, O. Gandy, \& A. Grant (Eds.), Framing public life: Perspectives on media and our understanding of the social world (pp. 175-184). Mahwah, NJ: Lawrence Erlbaum.

Cappella, J., \& Jamieson, K. (1996). News frames, political cynicism, and media cynicism. Annals of American Academy of Political \& Social Science, $546,71-84$.

Chen, L., \& Zillmann, D. (2002, August 9). Effects of lead frames on the selective reading of associated news reports. Paper presented in the scholar-toscholar session of the Newspaper Division of the Association for Education in Journalism and Mass Communication's national conference, Miami Beach, FL.

Davis, J. J. (1995). The effects of message framing on response to environmental communications. Journalism \& Mass Communication Quarterly, 72(2), 285-299.

De Vreese, C., \& Semetko, H. A. (2002). Cynical and engaged: Strategic campaign coverage, public opinion and mobilization in a referendum campaign. Communication Research, 29(6), 615-641.

Fallows, J. (1996). Breaking the news: How the media undermine American democracy. New York: Pantheon.

Fox, W. (1993). Writing the news: A guide for print journalists. Ames: Iowa State University Press.

Garrison, B. (1990). Professional news writing. Hillsdale, NJ: Lawrence Erlbaum.

Gitlin, T. (1980). The whole world is watching: Mass media in the making and unmaking of the news left. Berkeley: University of California Press.

Haskins, J. B. (1984). Morbid curiosity and the mass media: A synergistic relationship. In J. A. Crook, J. B. Haskins, \& P. G. Ashdown (Eds.), Morbid curiosity and the mass media: Proceedings of a symposium (pp. 1-44). Knoxville: University of Tennessee and the Gannett Foundation.

Hertog, J. K., \& McLeod, D. M. (2001). A multiperspective approach to framing analysis: A field guide. In S. Reese, O. Gandy, \& A. Grant (Eds.), Framing public life: Perspectives on media and our understanding of the social world (pp. 139-161). Mahwah, NJ: Lawrence Erlbaum.

Iyengar, S. (1991). Is anybody responsible? How television frames political issues. Chicago: University of Chicago Press.

Iyengar, S., \& Simon, A. (1991). News coverage of the Gulf crisis and public opinion: A study of agenda-setting, priming, and framing. Communication Research, 20(3), 365-383. 
Jasperson, A. E., Shah, D. V., Watts, M., Faber, R. J., \& Fan, D. P. (1998). Framing and the public agenda: Media effects on the importance of the federal budget deficit. Political Communication, 15(2), 205-224.

Knobloch, S., Dillman Carpentier, F., \& Zillmann, D. (2003). Effects of salience dimensions of informational utility on selective exposure to online news. Journalism \& Mass Communication Quarterly, 80(1), 91-108.

Knobloch, S., Hastall, M., Zillmann, D., \& Callison, C. (2003). Imagery effects on the selective reading of Internet newsmagazines. Communication Research, 30(1), 3-29.

Knobloch, S., \& Zillmann, D. (2002). Mood management via the digital jukebox. Journal of Communication, 52(2), 351-366.

MacDougall, C. D. (1968). Interpretative reporting. New York: Macmillan.

MacDougall, C. D., \& Reid, R. D. (1987). Interpretative reporting (Rev. ed.). New York: Macmillan.

McLeod, D. M., \& Detenber, B. H. (1999). Framing effects of television news coverage of social protest. Journal of Communication, 49(3), 3-23.

Neuman, W. R., Just, M. R., \& Crigler, A. N. (1992). Common knowledge. Chicago: University of Chicago Press.

Plutchik, R. (1987). Evolutionary bases of empathy. In N. Eisenberg \& J. Strayer (Eds.), Empathy and its development (pp. 38-46). Cambridge, UK: Cambridge University Press.

Price, V., Tewksbury, D., \& Powers, E. (1997). Switching trains of thought: The impact of news frames on readers' cognitive responses. Communication Research, 24(5), 481-506.

Rhee, J. W. (1997). Strategy and issue frames in election campaign coverage: A social cognitive account of framing effects. Journal of Communication, 47(3), 26-48.

Richards, T. (2001). Media and conflict portrayal: Finding alternatives to the "fighting frame" in news reporting. Retrieved from http://www.conflictres. org/vol184/trudie.htm

Scheufele, D. A. (1999). Framing as a theory of media effects. Journal of Communication, 49(1), 103-122.

Semetko, H. A., \& Valkenburg, P. M. (2000). Framing European politics: A content analysis of press and television news. Journal of Communication, 50(2), 93-109.

Shah, D. V., Domke, D., \& Wackman, D. B. (2001). The effects of value-framing on political judgment and reasoning. In S. Reese, O. Gandy, \& A. Grant (Eds.), Framing public life: Perspectives on media and our understanding of the social world (pp. 227-243). Mahwah, NJ: Lawrence Erlbaum.

Shoemaker, P. J. (1996). Hardwired for news: Using biological and cultural evolution to explain the surveillance function. Journal of Communication, 46(3), 32-47.

Smith, S. (1997, March 15). Developing news reflexes in framing stories. Paper presented at the Pew Center/RTNDF workshop "Civic Journalism: Doing it Daily," Chicago. Retrieved from http://www.pewcenter.org/doingcj/civiccat

Tankard, J. W. (2001). The empirical approach to the study of media framing. In S. Reese, O. Gandy, \& A. Grant (Eds.), Framing public life: Perspectives 
Communication RESEARCH • February 2004

on media and our understanding of the social world (pp. 95-106). Mahwah, NJ: Lawrence Erlbaum.

Tewksbury, D., Jones, J., Peske, M. W., Raymond, A., \& Vig, W. (2000). The interaction of news and advocate frames: Manipulating audience perceptions of a local public policy issue. Journalism \& Mass Communication Quarterly, 77(4), 804-829.

Valentino, N. A., Beckmann, M. N., \& Buhr, T. A. (2001). When the frame is gone: Revisiting the impact of "strategic" campaign coverage on citizens' information retention. Journalism \& Mass Communication Quarterly, 78(1), 93-112.

Valentino, N. A., Beckmann, M. N., \& Buhr, T. A. (2002). A spiral of cynicism for some: The contingent effects of campaign news frames on participation and confidence in government. Political Communication, 18(4), 347-367.

Valkenburg, P. M., Semetko, H. A., \& De Vreese, C. H. (1999). The effects of news frames on readers' thoughts and recall. Communication Research, 26(5), 550-569.

Zillmann, D. (1991). Empathy: Affect from bearing witness to the emotions of others. In J. Bryant \& D. Zillmann (Eds.), Responding to the screen: Reception and reaction processes (pp. 135-167). Hillsdale, NJ: Lawrence Erlbaum.

Zillmann, D. (1998). The psychology of the appeal of portrayals of violence. In J. H. Goldstein (Ed.), Why we watch: The attractions of violent entertainment (pp. 179-211). New York: Oxford University Press.

Zillmann, D. (2002). News effects. In J. R. Schement (Ed.), Encyclopedia of communication and information (Vol. 2, pp. 645-651). New York: Macmillan.

Zillmann, D., Knobloch, S., \& Yu, H. (2001). Effects of photographs on the selective reading of news reports. Media Psychology, 3, 301-324.

DolfZillmann (Ph.D., University of Pennsylvania, 1969) is Burnum Distinguished Professor Emeritus of communication and information sciences and of psychology at the University of Alabama. His research includes the exploration of message selection and exposure influence in both informative and entertaining media of communication.

Lei Chen (M.S., University of Alabama, 2003) is a doctoral candidate in the Mass Communications Program at the University of Alabama. Her research has focused on the choices and effects of media content in general. She is also interested in advanced methodology in communication research.

Silvia Knobloch (Ph.D., Institute of Journalism and Communication Research, University of Music and Drama, Hannover, Germany, 1999) is a visiting professor in the Department of Communication Studies, University of Michigan at Ann Arbor. Her research investigates media uses and effects: more specifically, selective exposure phenomena in news and entertainment as well as interactive media use. 
Zillmann et al. • Lead Framing and Selective Exposure

Coy Callison (Ph.D., University of Alabama, 2000) is an assistant professor in the School of Mass Communications at Texas Tech University. His research

focuses on the persuasive implications of communicator and distribution channel characteristics. 